\title{
Aquisição da escrita e teoria da otimidade: uma reflexão inicial ${ }^{1}$
}

\author{
Cátia de Azevedo Fronza \\ UNISINOS
}

\section{Abstract}

This paper is on children's writing in the first stages of Brazilian elementary education. These data are considered in a relationship between writing acquisition and speech acquisition, because similar aspects are noted in both process. Preliminary discussions are introduced on an interpretation of writing data with some assumptions on Optimality Theory. At first, it seems possible to understand writing as a similar process to speech, but much research is necessary. Seeing writing as a process is as important as what it has to do with speech acquisition. It's necessary to understand both processes as attempte to achieve the standard and these attempte also depend on cognitive and contextual factors. 


\section{INTRODUÇÃO²}

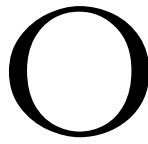

interesse desta autora pela aquisição da escrita deve-se ao estudo de Varella (1993), que destaca o fato de que as crianças, durante a alfabetização, utilizam, na escrita, processos fonológicos muito semelhantes aos observados na fala. Seguindo as reflexões de Varella (op. cit.), iniciou-se, em 2000, a investigação Textos nas séries iniciais: evidências fonológicas, na qual foram coletadas 326 produções espontâneas de 66 crianças que freqüentavam a $1^{\underline{a}}$ série em três escolas da rede privada de ensino de São Leopoldo. Com a conclusão desse estudo, em julho de 2001, foi possível identificar mais evidências para a relação entre a aquisição da escrita e da fonologia. Esse fato motivou outra pesquisa, concluída em janeiro de $2004,{ }^{3}$ com o objetivo de investigar o desenvolvimento da escrita nas demais séries iniciais, ou seja, na $2^{2}$, $3^{\underline{a}}$ e $4^{\underline{a}}$ séries das mesmas escolas que participaram do estudo de 2000-2001. Nas produções das crianças de ambas as pesquisas, observou-se que havia muito mais equivalências que diferenças em relação ao alvo pretendido e que a superação de dificuldades ortográficas se tornava evidente a cada texto. Nas palavras que mostraram alterações ou realizações diferentes da forma gráfica alvo, pode-se dizer que se evidenciou uma "fonologia" da escrita, ou seja, registraram-se ocorrências de não-realizações, reorganizações, inserções e alterações nos segmentos/letras, as quais, na maioria das vezes, provocaram mudanças de significado, concordando com resultados de Varella (1993). Quanto à aquisição das classes naturais, permitindo-se mais uma vez a aproximação com a fonologia, verificou-se que os sujeitos, na sua maioria, utilizavam adequadamente as letras que representam as plosivas e nasais, em primeiro lugar, 
seguidas das fricativas e, por último, das líquidas. Destaca-se que tal seqüência é semelhante ao que estudos sobre a aquisição da fonologia têm considerado como perfil de desenvolvimento fonológico normal, desde Yavas (1988), Lamprecht (1990) e Hernandorena (1990), entre outras pesquisas retomadas por Freitas (2004), Oliveira (2004) e Mezzomo e Ribas (2004).

Como se sabe, a maior parte das crianças, ao iniciar o processo de aquisição da escrita, já domina as estruturas lingüísticas da sua língua falada. Na produção escrita dos informantes das pesquisas ocorreram, por exemplo, casos de metátese e de redução de encontro consonantal. Isso permite afirmar que a escrita não é mera transcrição de fala. Se assim fosse, os sujeitos não escreveriam palavras com esses tipos de alterações, já que o seu desempenho oral estava de acordo com a idade. Por outro lado, destaca-se que tais reorganizações (metáteses) e não-realizações de segmentos/letras (redução de encontro consonantal, por exemplo) provocam mudanças na estrutura silábica das palavras. Seguindo Abaurre (1999, p. 179), pode-se dizer que as crianças, no início do processo de alfabetização, analisam a estrutura interna das sílabas, reorganizando suas representações fonológicas com o objetivo de adequar os constituintes silábicos e suas hierarquias. As palavras diferentes das convenções ortográficas são, muitas vezes, produto dessa análise. Considera-se significativo o fato de que as realizações que não correspondiam à escrita convencional, em muitos casos, eram equivalentes às formas faladas naturalmente por crianças de 2 a 4 anos. A busca pelo entendimento desse fato também é razão do estudo que não se esgota no âmbito deste texto.

Neste artigo, apresentam-se algumas reflexões sobre a possibilidade de analisar dados de aquisição da escrita de modo semelhante ao que se faz nos estudos sobre aquisição da fonologia, destacando alguns pressupostos da teoria da otimidade e a proposta de Lamprecht (2002) sobre a metátese, que, à primeira vista, parecem contribuir com os dados de escrita investigados, especialmente quanto à representação gráfica de encontros consonantais e às 
possibilidades de uso de consoantes em posição de coda. Os dados discutidos na seção 1 foram extraídos de um estudo-piloto, realizado em novembro de 2001, para atender às metas do estudo Produção de textos nas séries iniciais: evidências fonológicas e de textualidade. Os casos de escrita, na seção 2.2, foram obtidos pela investigação Textos nas séries iniciais: evidências fonológicas. Os informantes de ambos os estudos pertenciam a três escolas da rede privada de ensino de São Leopoldo, município da região metropolitana do Rio Grande do Sul. Informações sobre as coletas do estudo concluído no início de 2004 serão apresentadas oportunamente.

\section{OS DADOS}

Em novembro de 2001, foram coletados textos de $1^{\mathrm{a}}, 2^{\mathrm{a}}, 3^{\mathrm{a}} \mathrm{e}$ $4^{\underline{a}}$ séries das escolas da rede privada de ensino, SD, SJ e SL, no município de São Leopoldo, na região metropolitana do Rio Grande do Sul. A partir da motivação da professora de cada turma, foi produzida, de forma espontânea, uma narrativa (modalidade de texto adotada, em razão de a criança já ter vivenciado esse tipo de texto mesmo antes de chegar à escola e de possibilitar organização da seqüência lógico-temporal dos fatos). Este estudo foi realizado com a finalidade de, através dos levantamentos iniciais, registrar a produção escrita das crianças, no final de 2001, permitindo verificar sua evolução no ano de 2002, uma vez que a maioria delas mantevese nas escolas, cursando as $2^{\underline{a}}, 3^{\underline{a}}$ e $4^{\underline{a}}$ séries ( $1^{\underline{a}}, 2^{\underline{a}}$ e $3^{\underline{a}}$ séries em 2001).

De posse dos textos dos 268 informantes do estudo-piloto, realizou-se um levantamento inicial com a finalidade de identificar as alterações de escrita (cf. Fronza e Geremias, 2002, Fronza 2002, 2003a e 2003b) mais freqüentes nessas produções. O gráfico 1 apresenta dados desse levantamento. É importante dizer que, no eixo de valores do gráfico, está registrada a quantidade de ocorrências de cada alteração exemplificada nos comentários que sucedem o gráfico. As barras indicam o comportamento das alterações de acordo com cada série, conforme a legenda. ${ }^{4}$ 


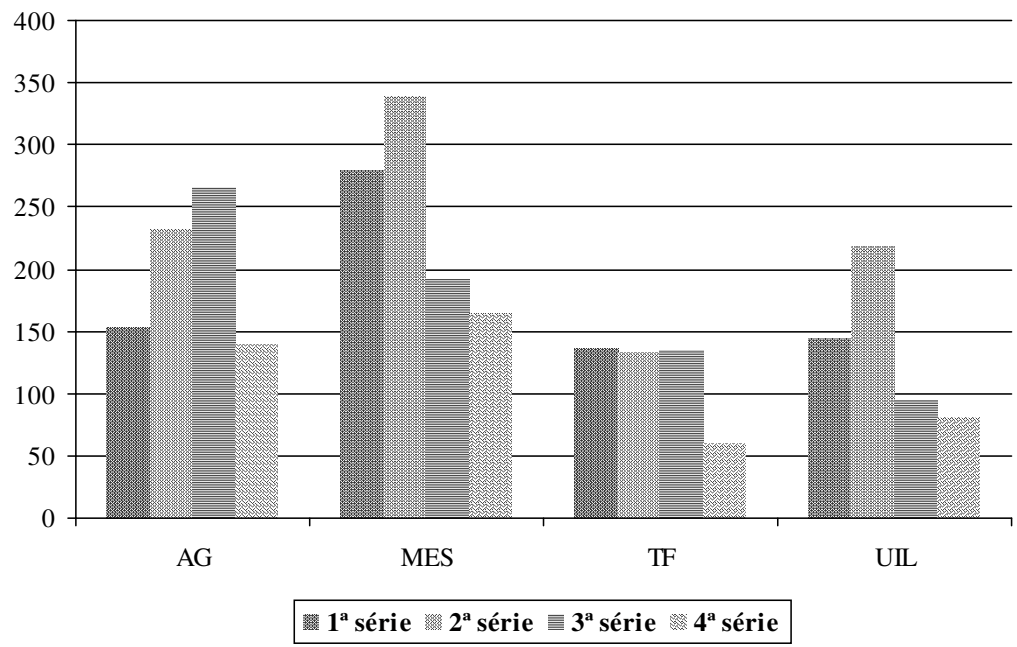

\section{GRÁFICO 1 - Alterações mais freqüentes (Estudo Piloto nov/2001)}

Partindo da proposta de Cagliari (1999), ${ }^{5}$ destacam-se como alterações mais freqüentes nos 268 textos a AG (Acentuação Gráfica), como em lápis $\rightarrow$ lapis; a TF (Transcrição Fonética), como verificase em balde $\rightarrow$ baudi e o UIL (Uso Indevido de Letra), como mostra mesa $\rightarrow$ meza. Essas ocorrências podem ser consideradas alterações ortográficas, porque representam diferenças quanto às convenções de escrita em nossa língua, conforme já destacou Varella (1993). Ocorrências de MES (Modificação na Estrutura Segmental/Seqüencial ${ }^{6}$ ), em que há inserções, reordenações, substituições e não-realizações de segmentos/letras, podendo provocar mudanças de significado, são consideradas, na pesquisa, como alterações fonológicas e, muitas vezes, equivalem a casos verificados na aquisição normal da fonologia por crianças dos 2 aos 4 anos.

Os dados do gráfico 1 permitem verificar que, apesar de haver muitas ocorrências de alterações ortográficas, a MES é a que mais registra casos na $1^{\underline{a}}$, na $2^{\underline{a}}$ e na $4^{\underline{a}}$ séries. Percebe-se também um aumento de casos de AG da $1^{\text {a }}$ para a $3^{\text {a }}$ série, diminuindo na $4^{\mathrm{a}}$. A TF, nas três primeiras séries, teve 136, 133 e 135 ocorrências, 
chegando a 60 na $4^{\mathrm{a}}$. O UIL apresentou 218 casos na $2^{\mathrm{a}}$ série, 144 na $1^{1}$, 95 na $3^{\text {a }}$ e 81 na $4^{\text {a }}$. Percebe-se, então, que a quantidade de casos de MES foi maior na $2^{\underline{a}}, 1^{\underline{a}}, 3^{\underline{a}}$ e $4^{\underline{a}}$ séries. A AG teve mais ocorrências na $3^{\mathfrak{a}}$ e na $2^{\underline{a}}$ séries. Em relação à $4^{\underline{a}}$ série, observa-se uma redução esperada na quantidade das alterações. Nesse nível de escolaridade, as crianças mostram seu conhecimento da escrita, já que estão em contato com essa modalidade da língua mesmo antes da $1^{\text {a }}$ série, em muitos casos.

\subsection{Modificação da Estrutura Segmental/Seqüencial (MES)}

Pelo fato de a MES representar casos de escrita que são muito semelhantes ao que se verifica na fala, depois de identificadas as alterações, decidiu-se observar o seu comportamento de acordo com a posição que ocupam na estrutura da sílaba e da palavra, além de considerar processos fonológicos como metátese e epêntese. Os exemplos a seguir ilustram os contextos, porém mais detalhes sobre esse levantamento serão apresentados em outra oportunidade. Optou-se por listar esses contextos para reforçar a hipótese de que é possível pensar nos dados de escrita de forma semelhante ao que se faz nos estudos sobre aquisição da fonologia.

a) Casos conforme posição na sílaba/palavra:?

- OM (Onset Medial): dinheiro $\rightarrow$ diero; todos $\rightarrow$ totos; foram $\rightarrow$ fola;

- OA (Onset Absoluto): joga $\rightarrow$ goga; gosta $\rightarrow$ costa; sua $\rightarrow$ cua;

- CM (Coda Medial): esperta $\rightarrow$ espeta; dentro $\rightarrow$ detro;

- CF (Coda Final): com $\rightarrow$ CO

b) Casos de epêntese:

- corajoso $\rightarrow$ coragioso;

- amigos $\rightarrow$ amiogos. 
c) Casos de metátese:

- fermento $\rightarrow$ fremento;

- pegar $\rightarrow$ pegra.

d) Casos de não-realização de sílaba:

- escola $\rightarrow$ isco;

- nada $\rightarrow$ na;

- casa $\rightarrow$ csa.

e) Casos de alterações de vogais:

- elefante $\rightarrow$ elifente;

- fugirão $\rightarrow$ fogerão.

Os exemplos registram casos de não-realizações, substituições e reorganizações de letras que resultam, muitas vezes, em mudanças na estrutura silábica, além de levar a mudanças de significado em relação ao alvo pretendido. Percebem-se, nos exemplos, palavras escritas muito semelhantes a formas faladas pelas crianças de 2 a 4 anos. Entre elas, destacam-se foram $\rightarrow$ ['fola]; esperta $\rightarrow$ [es'peta]; fermento $\rightarrow$ [fre'mẽ $\tilde{n}^{\mathrm{n}} \mathrm{tu}$. Diante desses e de outros casos de escrita, é pretensão desta autora uma discussão sobre as alterações correspondentes aos contextos, pois acredita que tais dados podem trazer muitas contribuições para o que se considera "fonologia" de escrita.

\section{TEORIA DA OTIMIDADE (TO) E AQUISIÇÃO DA FONOLOGIA}

Estudos sobre a aquisição da fonologia têm aproveitado as contribuições da teoria da otimidade, com base em Prince e Smolensky (1993), MacCarthy e Prince (1993), Prince (1995), Tesar e Smolensky (2000) e MacCarthy (2002). Tendo em vista o fato de que pesquisas sobre a aquisição da escrita (Varella, 1993; Fronza, 2002, 2003a, 2003b, 2003c; Fronza e Geremias, 2002; Fronza e Varella, 2003) têm verificado casos semelhantes à aquisição da fala dos $2 ; 0$ aos 4;0, reflete-se brevemente aqui sobre a possibilidade de a TO 
oferecer contribuições para ocorrências consideradas de natureza fonológica na aquisição da escrita, como as de reorganizações e nãorealizações de letras que levam a diferentes palavras e significados.

Partindo da idéia de que uma teoria fonológica deve fornecer uma explicação para discrepâncias entre competência fonológica e desempenho, talvez seja possível perguntar, se nos voltarmos à aquisição da escrita: haverá discrepâncias entre competência fonológica e desempenho de escrita? Poder-se-ia pensar ainda na relação entre Representações de input x Representações de output, ou seja, em que medida as representações subjacentes das palavras de nossa língua equivalem-se às representações escritas feitas pela criança em processo de alfabetização.

Com o intuito de verificar essa relação (competência desempenho), a teoria da otimidade apresenta um conjunto de restrições que, ranqueadas numa ordem particular, determinam qual output é mais harmônico com a gramática, considerado aqui o componente fonológico.

\subsection{Formalismo da TO}

De acordo com Bonilha (2003, p. 15), a TO é uma teoria dos Universais Lingüísticos e da Gramática Universal (GU) na qual as gramáticas das diversas línguas compartilham restrições simples e universais que podem ser violadas, mas que serão ranqueadas em hierarquias que determinarão cada língua. São propriedades básicas da TO, conforme McCarthy e Prince (1993, p. 5), a violabilidade, o ranqueamento, a inclusividade e o paralelismo.

Tendo como meta estabelecer a forma de input e de output e explicar a relação entre ambas, são necessárias duas entidades para mediar essa relação, como diz Archangeli (1997, p. 14):

- GEN, para determinado input, gera um número potencialmente infinito de candidatos a output;

- EVAL escolhe o output melhor, por considerar um conjunto de restrições universais. 
Pode-se dizer, então, que GEN cria, a partir de um input, candidatos a output, que serão avaliados por EVAL de acordo com o ranqueamento das restrições universais, cuja hierarquia é específica para cada língua, a fim de que seja selecionada a forma ótima. A variação entre as línguas é considerada em termos do ranqueamento relativo das restrições. ${ }^{8}$

As restrições da TO podem ser consideradas como Restrições de Fidelidade ou como Restrições de Marcação. As primeiras garantem que as representações de output assemelhem-se às representações de input, como MacCarthy e Prince (1993) exemplificam em:

- MAX: segmentos no input devem corresponder a segmentos no output (não há apagamento).

- DEP: segmentos no output devem corresponder a segmentos no input. (não há epêntese).

- MAX e DEP referem-se à fidelidade segmental.

- IDENT[traço]: os traços de ponto, de sonoridade e de modo dos segmentos do input devem superficializar-se nos segmentos correspondentes no output.

- IDENT refere-se à fidelidade de traço.

As Restrições de Marcação também são centrais à TO. São relevantes para dar conta de muitos fenômenos interlingüísticos, como destacam Barlow e Gierut (1999, p. 1484). Essas restrições exigem que as formas de output sejam não marcadas na estrutura. As propriedades não marcadas da língua são aquelas consideradas mais básicas, porque estão presentes em todas as gramáticas.

A TO está sendo muito utilizada para explicar dados da aquisição da fonologia, como registram os estudos apresentados por Matzenauer e Bonilha (2003). Num primeiro momento, no âmbito deste artigo, ela parece relevante para casos de escrita com seqüências de onsets complexos, como será comentado a seguir. Sabe-se que há necessidade de mais investigação, mas tais contextos chamam a atenção, porque, considerando a fala das crianças de 6 a 10 anos, informantes das pesquisas já mencionadas, em processo de 
alfabetização, supõe-se que não deveriam aparecer nos textos palavras como pisisava (precisava). Ocorrências desse tipo parecem remeter a uma característica de aquisição de escrita equivalente à de que a maioria das crianças domina, na fala, a seqüência CCV tardiamente, em torno de 5;0, conforme Ribas (2004). Então, poderse-ia dizer que também na escrita tal seqüência silábica é de aquisição tardia. Essa hipótese merece ser investigada.

Até esta reflexão, não se teve acesso a estudos sobre a aquisição da escrita com base na teoria da otimidade. O que se coloca aqui é o resultado de uma reflexão que precisa ser aprofundada a fim de que se verifique, com mais dados e mais estudos, se a teoria pode explicar o que se observa na "fonologia" da escrita. Um passo na busca da explicitação do que as crianças sabem sobre sua língua em relação ao que escrevem (no caso de onsets complexos) pode ser motivado pelo estudo de Lamprecht (2002), considerando dados de fala, em que a metátese é caracterizada como uma janela que permite ver o processo de ranqueamento de restrições que dá conta de realizações para alvos com onsets complexos. Por exemplo, tendo como alvo a palavra ['bru $\int a$ ], a criança ora fala ['bu $\int a$ ], ora ['bur $\left.\int a\right]$. Na tentativa de desfazer uma sílaba CCV, que, conforme Ribas (2004), é a última adquirida no português, a criança omite um segmento, a líquida, ou preserva-o, colocando-o em posição de coda silábica. Realizações escritas da palavra bruxa, apresentadas a seguir, foram retiradas do texto de uma menina de $1^{\mathrm{a}}$ série, redigido em novembro de 2000. Além dessas ocorrências, registraram-se os casos de: persente (presente); porcurar (procurar); incontaram (encontraram); tarbalhando (trabalhando) e senper (sempre). Seguindo a reflexão de Lamprecht (2002), destaca-se que as metáteses verificadas nos casos de escrita podem ser chamadas de intrassilábicas, pois a consoante líquida muda de posição na mesma sílaba, deixando de ser onset para ser coda, como registram a maior parte dos exemplos.

Sem entrar em mais detalhes no formalismo e nos fundamentos da teoria da otimidade, segue-se o ranqueamento das restrições 
proposto por Lamprecht (2002, p. 153) no qual se inserem a restrição de marcação, *COMPLEXO (encontros consonantais são proibidos), e as restrições de Fidelidade, MAX (uma consoante no input tem uma correspondente no output) e LINEARIDADE (não há metátese).

Para os estágios que levam à realização do onset complexo têm-se, então:

a) $\mathrm{E}_{1}$ : não-realização da líquida ['bu $\left.\int \mathrm{a}\right]$ *COMPLEXO $>>$ LINEARIDADE $>>$ MAX

b) $\mathrm{E}_{2}$ (intermediário, não evidenciado por todos os sujeitos): metátese ['bur $\left.\int a\right]$

*COMPLEXO >> MAX >> LINEARIDADE

c) $\mathrm{E}_{3}$ : onset complexo ['bru $\left.\int \mathrm{a}\right]$

\section{*MAX, LINEARIDADE >>*COMPLEXO}

Como se pode observar, a), b) e c) apresentam as mesmas restrições, porém o que determina o output é a hierarquia, que muda em cada estágio. Para que a forma ótima seja ['bru $\int a$ ], a restrição que impede onsets complexos tem que mudar de posição na hierarquia, ou seja, precisa estar ranqueada abaixo das restrições MAX e LINEARIDADE.

Tais ranqueamentos parecem explicar também os casos presentes no texto referido e em outros já analisados. Essas ocorrências não foram exclusivas de uma criança: com maior ou menor freqüência, a estrutura CCV foi modificada em vários textos, ora pelo apagamento da líquida (na maioria dos casos), ora pela metátese.

É possível dizer que, ao usarem estruturas complexas (CCV, por exemplo) na escrita, as crianças mostram ocorrências semelhantes ao que se tem observado na aquisição inicial de fala, as quais, com a evolução da alfabetização, aproximam-se e equivalem-se ao alvo adulto (há um texto da mesma criança que, na segunda série, usou adequadamente onsets complexos). A princípio, a teoria da otimidade 
pode oferecer contribuições para reflexões promissoras sobre o processo de construção da escrita, pois, como nos estudos sobre a aquisição da fonologia, parece haver restrições de fidelidade e de marcação que determinam o output realizado pela criança em cada fase. Se o contato com a modalidade escrita aumentar no decorrer do processo, diferentes ranqueamentos das restrições propiciarão outputs que tendem a ser os mesmos do alvo adulto. O fato de as mesmas restrições estarem presentes na gramática do adulto e na da criança, conforme destacam Barlow e Gierut (1999), apesar de diferentes ranqueamentos, e o de a percepção inicial de essas restrições parecerem explicar fatos de aquisição da escrita reforçam o valor explanatório da teoria da otimidade. Outros estudos, inclusive, poderiam ser utilizados aqui, como se fez com o de Lamprecht (2002), destacandose o de Matzenauer (2003), para encontrar mais evidências. Esta é mais uma pretensão da autora deste artigo.

\subsection{Aquisição da fonologia e aquisição da escrita: mais semelhanças}

A partir de alguns dados da pesquisa Texto nas séries iniciais: evidências fonológicas (2000-2001), na qual foram coletadas produções escritas de 3 turmas de $1^{\text {a }}$ série (326 textos) de 3 escolas da rede de ensino privado de São Leopoldo, pretende-se discutir algumas semelhanças entre dados da escrita e da fala.

Dados:

- Menina falante monolíngüe do PB

- $1^{a}$ série (São Leopoldo - RS)

- Desenvolvimento normal

- Casos de EC/Met/Coda 
QUADRO 1

Palavras em destaque

\begin{tabular}{|c|c|}
\hline Palavra & Realização \\
\hline \multicolumn{2}{|c|}{ Texto A - maio 2000} \\
\hline entraram & entaro \\
\hline \multicolumn{2}{|c|}{ Texto B - junho 2000} \\
\hline $\begin{array}{l}\text { barco } \\
\text { precisava } \\
\text { grandes }\end{array}$ & $\begin{array}{l}\text { braco } \\
\text { pisisava } \\
\text { gardes }\end{array}$ \\
\hline \multicolumn{2}{|c|}{ Texto F - outubro 2000} \\
\hline $\begin{array}{l}\text { atrás } \\
\text { transformou }\end{array}$ & $\begin{array}{l}\text { a taris } \\
\text { tanformou }\end{array}$ \\
\hline \multicolumn{2}{|c|}{ Texto G - novembro 2000} \\
\hline $\begin{array}{l}\text { comprar } \\
\text { presente } \\
\text { procurar } \\
\text { encontraram } \\
\text { bruxa } \\
\text { trabalhando } \\
\text { bruxa } \\
\text { sempre }\end{array}$ & $\begin{array}{l}\text { compar } \\
\text { persente } \\
\text { porcurar } \\
\text { incontaram } \\
\text { burxa } \\
\text { tarbalhando } \\
\text { buxa } \\
\text { senper }\end{array}$ \\
\hline
\end{tabular}

O quadro 1 apresenta palavras escritas em 4 textos produzidos no ano de 2000 pela informante. Fez-se questão de destacar as ocorrências relacionadas aos encontros consonantais, nas quais aparecem apagamento da consoante líquida, como em 'entaro', e casos em que a consoante líquida muda sua posição, como na palavra 'persente'. É interessante observar que, no texto G, a quantidade de palavras com essas características foi maior. O quadro evidencia duas ocorrências da palavra bruxa, além de outras que registram as diferentes grafias de sílabas CCV que se tornam CV ou CVC. Tais casos podem, a princípio, ser explicados a partir da proposta de Lamprecht (2002) sobre a metátese. O que se verifica é que a informante escreveu palavras que se encontram entre os estágios 1 e 2, conforme Lamprecht (2002). Há uma única ocorrência de CCV, na palavra barco, que se tornou braco. Remete-se aqui à afirmação de Abaurre (1999, p. 179), já mencionada, indicando que 
a criança parece analisar a estrutura interna das sílabas, através de reorganizações, cuja meta é chegar ao sistema de escrita da sua língua.

\section{QUADRO 2}

Exemplos de alterações envolvendo EC

Escola SD

\begin{tabular}{l|l|l|l|l|l}
\hline \multicolumn{2}{c|}{$1^{\underline{a}}$ série } & \multicolumn{2}{c|}{$2^{\underline{\underline{a}}}$ série } & \multicolumn{2}{c}{$4^{\underline{a}}$ série } \\
\hline Palavra & Realização & Palavra & Realização & Palavra & Realização \\
\hline flor & for & comprar & conparar & briga & biga \\
\hline--- & --- & próximo & paxima & aprendizes & apendizes \\
\hline
\end{tabular}

Escola SL

\begin{tabular}{l|l|l|l|l|c}
\hline \multicolumn{2}{c|}{$1^{\underline{a}}$ série } & \multicolumn{2}{c|}{$2^{\underline{a}}$ série } & \multicolumn{2}{c}{$3^{\underline{a}}$ série } \\
\hline Palavra & Realização & Palavra & Realização & Palavra & Realização \\
\hline monstro & mosto & abriu & abiu & grande & gade \\
\hline brilhante & bilha & trouxe & troxe & -- & -- \\
\hline pegar & pegra & braba & baba & --- & -- \\
\hline
\end{tabular}

Escola SJ

\begin{tabular}{l|l|l|l|l|l|l|l}
\hline \multicolumn{2}{c|}{$1^{\underline{a}}$ série } & \multicolumn{2}{c|}{$2^{\underline{a}}$ série } & \multicolumn{2}{c|}{$3^{\underline{a}}$ série } & \multicolumn{2}{c}{$4^{\underline{a}}$ série } \\
\hline Palavra & Realização & Palavra & Realização & Palavra & Realização & Palavra & Realização \\
\hline abraço & abaso & subiu & subriu & presentes & pesentes & precisa & pescisa \\
\hline primeira & pimera & grande & rãnde & brinquedo & brinque & brincadeiras & bincadeiras \\
\hline brincadeira & bicadera & pobre & pobel & brinquedos & brinque & -- & --- \\
\hline travesseiro & teraveseiro & brincar & bincar & --- & -- & --- & --- \\
\hline--- & --- & sempre & senrpê & --- & --- & --- & --- \\
\hline
\end{tabular}

No quadro 2 apresentam-se exemplos de palavras com alterações relacionadas aos encontros consonantais, verificadas nos textos de alguns alunos, de acordo com séries e escolas. Percebemse muitos casos de apagamento da consoante líquida e mudanças de posição de algumas letras no contexto da sílaba/palavra (metátese). É interessante observar que há apenas um registro de não-realização de consoante plosiva (grande $\rightarrow$ rãnde). Tal ocorrência também é rara na fala. Estão listadas no quadro, ainda, algumas ocorrências de epêntese e de substituição de letras. Apesar de não representarem o maior número de alterações nos textos das crianças, 
muitas das palavras assemelham-se às produções de fala de crianças de 2 a 5 anos. E, como já se disse, merecem ser estudados também a partir dos pressupostos da TO.

Uma simples observação poderia considerar que os dados do quadro 2 registram meras trocas de posição das letras. Como destaca Abaurre (1999, p. 176), são exemplos "absolutamente normais, representativos da complexa relação existente entre as estruturas da oralidade e aquelas da escrita”. O professor deve refletir a respeito dessas ocorrências, não simplesmente ignorá-las ou acentuar tais casos como "erros" de escrita, que mostram que os alunos "não sabem escrever". Para isso, o professor precisa estar consciente das relações que se estabelecem na escrita de seus alunos, podendo receber auxílio de estudos que são capazes de explicitar tais relações.

\section{CONSIDERAÇÕES FINAIS}

Esta reflexão teve como meta apresentar dados de escrita que mostram semelhanças aos dados verificados na aquisição da fala por muitas crianças de 2 a 5 anos. Partindo do fato de que a escrita é um processo de muita expectativa e ansiedade de pais, professores e alunos, registram-se dados que indicam que os erros convencionais sempre ocorrem, porém verificam-se mais adequações do que inadequações nos textos das crianças. É importante destacar que as incorreções não são dificuldades insuperáveis ou falta de capacidade das crianças e que os acertos não surgem casualmente. Mesmo que a oralidade exerça muita influência sobre a escrita, esta não é transcrição daquela.

Antes de qualquer coisa, deve-se considerar que escrever é um ato em que a criança precisa dar-se conta dos sons e de suas relações grafêmicas. Nesse ato, ela utiliza estratégias que simplificam estruturas que lhe são complexas, como já fez durante a sua aquisição de fala. Para que o professor possa estar ciente do sistema de escrita utilizado pelos seus alunos, ele deve promover a escrita espontânea, quando o aprendiz pode usar realmente o seu saber, indicando ocorrências fonológicas que fornecem pistas para que o professor organize sua prática pedagógica. 
A ocorrência de dados de fala e de escrita semelhantes permitiu uma breve discussão sobre a possibilidade de utilizar fundamentos da teoria da otimidade nos contextos aqui apresentados. Sabe-se que tais reflexões são prematuras e que há necessidade de mais estudos. Por outro lado, há indicadores de que é possível pensar na aquisição de um sistema fonológico de escrita semelhante ao que é evidenciado por crianças de desenvolvimento fonológico normal. Os estudos continuam.

\section{NOTAS}

${ }^{1}$ Este artigo é uma adaptação da comunicação A teoria da otimidade e a aquisição da escrita: uma possibilidade de análise, apresentada no GT de Fonética e Fonologia da ANPOLL, durante o XVII Encontro Nacional da ANPOLLL, realizado na cidade de Gramado, em junho de 2002.

${ }^{2}$ Registra-se um agradecimento a Cristiane Gomes e a Patricia Beatriz Lemes, pelo auxílio na revisão do artigo, trazendo à tona discussões relevantes.

${ }^{3}$ É importante mencionar que essa pesquisa contou com o apoio da bolsista UNIBIC, Aline Lorandi, no período de agosto de 2001 a julho de 2003, das bolsistas FAPERGS, Karen Cristiani Staudt e Renata Trindade Severo, durante o ano de 2002, e de Patrícia Beatriz Lemes, bolsista FAPERGS, no ano de 2003.

${ }^{4}$ Tem-se consciência de que uma das limitações do estudo reside no fato de que não se apresenta aqui um tratamento estatístico para os dados, apenas se indica o número de ocorrências. Trabalhos futuros deverão apresentar análises quantitativo-qualitativas que serão possíveis com o uso do pacote de programas estatísticos Varbrul.

${ }^{5}$ A proposta de Cagliari (1999) norteou os estudos desta autora, mas os trabalhos de Carraher (1990), Morais (1998), Zorzi (1998), Lemle (1998) e Tessari (2002), entre outros, também fundamentam a busca de uma classificação das alterações capaz de melhor explicitar os dados de escrita.

${ }^{6}$ É importante dizer que, embora não explicitadas aqui, as modificações de estrutura segmental apresentam alterações numa única letra ou em duas letras que representam um único som, não ocasionando mudança na estrutura silábica, e as de estrutura seqüencial correspondem às mudanças que alteram a seqüência silábica, como no caso de fermento, que se torna "fremento" (CVC > CCV). 
${ }^{7}$ OA corresponde, na identificação de posição de estrutura de sílaba e de palavra, a Início de Sílaba, Início de Palavra; OM diz respeito a Início de Sílaba, Dentro da Palavra; CM representa Final de Sílaba, Dentro de Palavra; e CF equivale a Final de Sílaba, Final de Palavra.

${ }^{8}$ A abrangência deste trabalho não permite mais aprofundamentos teóricos. Recomenda-se a leitura de Bonilha (2003), que apresenta uma reflexão pertinente sobre GEN, além de sistematizar as bases da TO, e de Collischonn e Schwindt (2003), que discutem conceitos principais da teoria da otimidade e sua relação com as demais teorias fonológicas.

\section{REFERÊNCIAS BIBLIOGRÁFICAS}

ABAURRE, Maria Bernardete. Horizontes e limites de um programa de investigação em aquisição da escrita. In: LAMPRECHT, R. R. (Org.). Aquisição da linguagem: questões e análises. Porto Alegre: EDIPUCRS, 1999. p. 167-186.

ARCHANGELI, Diana. Optimality Theory: an introduction to Linguistics in the 1990. In: ARCHANGELI, Diana; LANGEDOEN, D. Terence (Ed.). Optimality Theory: an overview. Oxford: Blackwell, 1997.

BARLOW, Jessica A.; GIERUT, Judith A. Optimality Theory in Phonological Acquisition. Journal of Speech, Language, and Hearing Research, v. 42, p. 14821498, 1999.

BONILHA, Giovana F. G. Teoria da Otimidade. In: MATZENAUER, C. L. B.; BONILHA, G. F. G. Aquisição da fonologia e teoria da otimidade. Pelotas: EDUCAT, p. 13-24, 2003.

CAGLIARI, Luiz Carlos. Alfabetização e lingüistica. São Paulo: Scipione, 1999.

CARRAHER, Terezinha Nunes. Explorações sobre o desenvolvimento da ortografia em Português. In: Isto se aprende com o ciclo básico. São Paulo: SE/CENP, 1990. p. 114-122.

COLLISCHONN, Gisela; SCHWINDT, Luiz Carlos. Teoria da Otimidade em fonologia: rediscutindo conceitos. In: HORA, Dermeval da; COLLISCHON, Gisela. Teoria Lingüistica: fonologia e outros temas. João Pessoa: Editora Universitária/ UFPB, 2003.

FREITAS, Gabriela Castro Menezes de. Sobre a aquisição das plosivas e nasais. In: LAMPRECHT, Regina Ritter (Org.). Aquisição fonológica do português: perfil do desenvolvimento e subsídios para terapia. Porto Alegre: Artmed, 2004. p. 73-81. 
FRONZA, Cátia. A teoria da otimidade e a aquisição da escrita: uma possibilidade de análise. Comunicação apresentada no XVII ENCONTRO NACIONAL DA ANPOLL, Gramado, 2002.

. Textos nas séries iniciais: evidências fonológicas - resultados preliminares. In: II CONGRESSO INTERNACIONAL DA ABRALIN, Anais... Fortaleza: Imprensa Universitária/UFC, p. 103-105, 2003 a.

. Fonética/Fonologia do PB e a ortografia nas séries iniciais. Comunicação apresentada no 51ํㅡㄴ SEMINÁRIO DO GEL. Taubaté: UNITAU, 2003b.

Reflexões sobre aspectos de aquisição fonológica na escrita de alunos de séries iniciais. Comunicação apresentada no $6^{\circ}$ ENCONTRO NACIONAL SOBRE AQUISIÇÃO DA LINGUAGEM, Porto Alegre, 2003c.

FRONZA, Cátia; GEREMIAS, V. R. Características fonológicas presentes na alfabetização. In: VI CONGRESSO BRASILEIRO DE LINGÜÍSTICA APLICADA, Anais... Belo Horizonte: VI CBLA (CD-ROM), v. 1, p. 1-10, 2002.

FRONZA, Cátia; VARELLA, N. K. Aspectos fonológicos nos textos de crianças em alfabetização. Textura: Canoas, v. 8, p. 39-48, 2003.

HERNANDO RENA, Carmen Lúcia Matzenauer. Aquisição da fonologia do português: estabelecimento de padrões com base em traços distintivos. 1990. Tese (Doutorado) - PUCRS, Porto Alegre.

LAMPRECHT, Regina Ritter. Perfil da aquisição normal da fonologia do português: descrição longitudinal de 12 crianças: 2:9 a 5:5. 1990. Tese (Doutorado) - PUCRS, Porto Alegre.

. Metathesis in Phonological Acquisition: a window to constraint ranking in the Child's system. In: Costa, J. e Freitas, M. J. (Org.). GALA 2001 Conference on Language Acquisition, Lisboa, ALP, v. 1, p. 149-154, 2002.

LEMLE, Miriam. Guia teórico do alfabetizador. São Paulo: Ática, 1998.

MACCARTHY, John. A Thematic Guide to Optimality Theory. Cambridge: University Press, 2002.

MACCARTHY, John; PRINCE, A. Prosodic Morphology. New Brunswick: Rutgers University Center for Cognitive Science, 1993.

MATZENAUER, C. L. B. Aquisição da linguagem e otimidade: uma abordagem com base na sílaba. In: MATZENAUER, C. L. B e BONILHA, G. F. G. Aquisição da fonologia e teoria da otimidade. Pelotas: EDUCAT, p. 55-65, 2003.

MATZENAUER, C. L. B.; BONILHA, G. F. G. Aquisição da fonologia e teoria da otimidade. Pelotas: EDUCAT, 2003. 
MEZZOMO, Carolina Lisboa; RIBAS, Letícia Pacheco. Sobre a aquisição das líquidas. In: LAMPRECHT, Regina Ritter (Org.). Aquisiçãofonológica do português: perfil do desenvolvimento e subsídios para terapia. Porto Alegre: Artmed, p. 95109, 2004.

MORAIS, Artur Gomes de. Ortografia: ensinar e aprender. São Paulo: Ática, 1998.

OLIVEIRA, Carolina Cardoso. Sobre a aquisição das fricativas. In: LAMPRECHT, Regina Ritter (Org.). Aquisiçãofonológica do português: perfil do desenvolvimento e subsídios para terapia. Porto Alegre: Artmed, 2004. p. 83-94.

PRINCE, A. Introduction to Optimality Theory. Conferência em Nijmegen University, 1995.

PRINCE, A.; SMOLENSKY, P. Optimality Theory. Constraint Interaction in Generative Grammar. New Brunswick: Rutgers University Center for Cognitive Science, 1993.

RIBAS, Letícia Pacheco. Sobre a aquisição do onset complexo. In: LAMPRECHT, Regina Ritter (Org.). Aquisiçãofonológica do português: perfil do desenvolvimento e subsídios para terapia. Porto Alegre: Artmed, 2004. p. 151-164.

TESAR, B.; SMOLENSKY, P. Learnability in Optimality Theory. Massachusetts: MIT Press, 2000.

TESSARI, Elita. Operações fonológicas nas alterações ortográficas - a presença da fonologia na ortografia. 2002. Dissertação (Mestrado) - UCPel, Pelotas.

VARELLA, Noely Klein. Na aquisição da escrita pelas crianças ocorrem processos similares aos da aquisição da fala? 1993. Dissertação (Mestrado) - PUCRS, Porto Alegre.

YAVAS, Mehmet. Padrões na aquisição da fonologia do português. Letras de Hoje, Porto Alegre, v. 23, n. 3, p. 7-30, dez. 1988.

ZORZI, J. L. Aprender a escrever: a apropriação do sistema ortográfico. Porto Alegre: Artes Médicas, 1998. 